\title{
Helpseeking and Pathways to Care in the Early Stages of Psychosis
}

Fridgen $\mathrm{GJ}^{1 \mathrm{a}}$, Aston $\mathrm{J}^{2^{*} \mathrm{a}}$, Gschwandtner $\mathrm{U}^{2}$, Pflueger $\mathrm{M}^{2}$, Zimmermann $\mathrm{R}^{2}$, Studerus $E^{2}$, Stieglitz RD ${ }^{2}$, Riecher-Rössler $\mathrm{A}^{2^{*}}$

${ }^{1}$ Bezirkskrankenhaus Landshut, Prof. Buchner-Str. 22, D-84034 Landshut, Germany

${ }^{2}$ University of Basel Psychiatric Clinics, Petersgraben 4, CH-4031 Basel, Switzerland

${ }^{\mathrm{a}} \mathrm{G}$. Fridgen and J. Aston both contributed equally to the work

*Corresponding Author

Prof. Dr. Anita Riecher-Rössler, MD

University of Basel Psychiatric Clinics

Center for Gender Research and Early Detection

c/o University Hospital Basel

Petersgraben 4

CH-4031 Basel, Switzerland

Tel.: +41612655114

Fax: +41612654599

E-mail: Anita.Riecher@upkbs.ch 


\section{Abstract}

Purpose: Delay in the treatment of a first psychotic episode can have a negative influence on the future course of the disease. In this context, it is important to examine pathways to care in order to understand factors contributing to delay in access to adequate care.

Methods: Using the Basel Interview for Psychosis (BIP), we examined the help-seeking behaviour of 61 individuals with an At-Risk Mental State (ARMS) for psychosis and 37 patients with a First Episode of psychosis (FE) in a low threshold health care system as part of the Basel early-detection-of-psychosis (FePsy) study.

Results: The median duration of untreated illness (DUI) was 3.4 years, of untreated psychosis (DUP) 12 months. Eighty-six per cent of all individuals sought help of some kind before reaching our specialised early detection outpatient clinic, with a mean number of help-seeking contacts of 1.5 prior to referral. The most frequent first help-seeking contacts were family members or relatives $n=24(26.7 \%)$, close friends $n=17(17.9 \%)$, psychiatrists in private practice $n=13(14.4 \%)$ or general practitioners $n=11(12.2 \%)$. Most patients consulted other health professionals in the early course of the illness before reaching our specialised service; help-seeking with non-medical institutions was rare. Women had more help-seeking contacts than men before contact with our early detection clinic.

Conclusions: Family, close friends and medical professionals play an important role in helpseeking leading to specialised psychiatric care. Men seek help less often; specific strategies for encouraging young, at risk men to seek help should be developed.

Keywords: psychosis, early diagnosis, pathways to care, help seeking, gender 


\section{Introduction}

Schizophrenic psychoses often begin with uncharacteristic symptoms such as impaired functioning, social withdrawal, poor concentration or apathy [1-3]. Several studies show that patients with psychotic disorders experience psychotic symptoms for an average of 1-2 years before appropriate antipsychotic treatment is initiated [2,4-7]. The duration of untreated psychosis (DUP) has been shown to be associated with more severe symptoms, worse treatment response, increased risk for relapse and poor overall outcome [8-14], in at least some sub-groups of first episode patients [15]. Untreated psychosis has negative effects on the individuals' social networks, vocational and educational achievements [16-18]. It is therefore important to recognise and treat psychosis as early as possible.

One factor that may contribute to psychosis not being treated in time is difficulties in finding the right help-seeking contact. Pathways to care are influenced by various factors such as gender, cultural and economic background or the social network of the individual [19-24]. Social withdrawal, lack of social network, belonging to an ethnic minority, being unemployed or single or having negative stereotypes about psychiatric diseases hinder help-seeking efforts [20,21,23]. Furthermore, pathways to care depend on structure and accessibility of local (mental) health care systems.

The majority of patients with psychotic disorders had been help-seeking for other mental disorders in secondary mental health care, most commonly mood and anxiety disorders and substance use disorders, prior to onset of psychosis [25]. In some countries general practitioners function as gatekeepers to specialised health care [26,27]. In other countries, where patients have free access to health specialists such as psychiatrists or psychologists, pathways to care are different, but general practitioners probably remain important.

Most people experiencing early psychosis contact a health professional as a first point of contact [21]. Especially in emerging psychosis, general practitioners play a key role in the help-seeking efforts [9,22,28-35]. Also, many individuals with an at-risk mental state (ARMS) for psychosis [36,29] or patients with a first episode 
of psychosis (FE) consult a psychiatrist or specialised outpatient department as a first help-seeking contact [29,30,34,35].

This study expands upon earlier investigations of pathways to care in early psychosis in different ways: In the examined area, an early detection program was newly introduced in 1998. A broad information campaign including scientific symposia, teaching courses for general practitioners, psychiatrists and social service staff, articles in local newspapers and a website [37] were started. It is therefore interesting to examine pathways to care after the introduction of this wide information campaign. A wide range of possible pathways to care were explored. Individuals could declare up to 15 different contacts, professional or lay ones. Most other studies only present data about pathways to care via the health care system such as general practitioners or psychiatrists.

We also present data about pathways to care in both ARMS individuals and patients with a first episode psychosis (FE). Only few data are available for both groups.

Additionally, only little data is available up to now about gender differences in this group of patients, so we examined differences between men and women in pathways to care in the early stages of psychosis.

\section{Objectives}

The aim of the study was to examine the help-seeking behaviour of ARMS individuals or FE in a low threshold system with easy access to mental health care facilities, in which a specialised early detection clinic was newly established. Specific aims were to investigate

- the duration of untreated illness (DUI) as well as the duration of untreated psychosis (DUP);

- all first and subsequent help-seeking contacts and the contacts which resulted in the referral to our specialised clinic. 
Differences between individuals with an ARMS and FE as well as gender differences were analysed.

\section{Methods}

\section{Setting and recruitment}

Access to mental health services in the catchment area is low threshold; medical insurance obligatory for all inhabitants of the country covers the majority of the costs. In the catchment area there are also psychiatrists in private practice and general practitioners, both with the possibility of referring to the university outpatient clinic. There is also the main university psychiatric hospital providing most of the inpatient psychiatric care, and one private clinic providing mainly inpatient psychiatric care. Before and during our study period, all these facilities were successfully asked to refer all patients with a suspected prodromal or first episode state to our clinic. Cooperation was intense, so that we probably saw most of these patients. According to well established incidence figures we would have expected 10 first episode patients per 100.000 inhabitants, which for the 200.000 inhabitants of the canton of Basel would amount to 80 FE Patients over 4 years. In fact we count 91, which confirms that we saw most of these patients.

The study was part of the $\boldsymbol{F E P S Y}$ study (Früherkennung von Psychosen: Early Detection of Psychosis). This study has been described in detail elsewhere [3739]. In short, subjects were recruited into the study via our specialised outpatient clinic at the Psychiatric University Outpatient Department of the Psychiatric University Clinics Basel (see Figure 1). For screening and assessment of the atrisk mental state, the Basel Screening Instrument of Psychosis (BSIP) was used [40]. Individuals were assessed and classified as ARMS, FE patients or "not at risk for psychosis" (other psychiatric diseases) [37-39]. With the BSIP a rating of the at risk mental state as well as the transition criteria can be done, according to Yung et al 1998 [36]. The BSIP was developed based on these criteria around the same time as the Comprehensive Assessment of At-Risk Mental States (CAARMS) [41], using the same criteria, there is one difference in that a low risk category with unspecific prodromal signs is also included.

Our inclusion criteria are shown in Tables 1 and 2. 
In order to give an impression of the composition of the FE group, we have summarized the clinical ICD-10 diagnoses in Table 3 [42]. Most of these diagnoses were reached in the weeks after the first initial assessment with the BSIP.

Table 3. Overview of clinical ICD-10 diagnoses in the FE group

Exclusion criteria were: age below 18 years, insufficient knowledge of German, IQ $<70$, previous episode of schizophrenic psychosis (treated with major tranquilizers for $>3$ weeks), psychosis clearly due to organic reasons or substance abuse, or psychotic symptoms within a clearly diagnosed depression or borderline personality disorder [37].

An overview of the recruitment process of the study sample is given in Figure 1.

Figure 1. Overview on the recruitment process of the study sample

Information about the help-seeking behaviour was obtained using a specifically developed interview, the Basel interview for psychosis, BIP (Riecher-Rössler et al, in preparation).

The study was approved by the local ethics committee of the University of Basel and written informed consent was obtained from all participants.

\section{Basel Interview for Psychosis (BIP)}

After having included subjects based on the screening with the BSIP in a next assessment step an extensive entry examination with a specifically developed extensive interview for the early detection of psychosis, the BIP (Riecher-Rössler et al, in preparation) was done. This interview allows a standardised history taking in patients with (emerging) psychosis. It is based on the IRAOS [7] and also on other indicators and predictors of beginning psychosis as known from the literature. 
The first section contains questions about the social and physical development of the individual, developmental problems and disorders, school and education, employment situation, partnership, physical diseases, and previous mental disorders and drug use, as well as the psychiatric family history. A second section of the interview assesses indicators and symptoms for a beginning psychosis. The main reasons for the consultation as well as early signs and the first perceived change in well-being of the individual are asked about. Prodromal signs such as anxiety, difficulties in concentrating, compulsion, social decline, and a range of (pre-) psychotic symptoms and their onset, such as suspiciousness, subthreshold hallucinations and delusions, are assessed.

The third, relatively short section covers the vulnerability of the individual, which means feeling strain, emotional pressure under certain circumstances such as conflicts, or working in a loud environment or under time pressure.

The fourth section investigates the help-seeking strategies and pathways to care. It covers whether the subject made any help-seeking attempt at all before coming to the early detection clinic, which person was contacted first along the help-seeking pathways and which persons or institutions were contacted subsequently (after the first help-seeking contact). The following help-seeking attempts are specifically asked about: family/relatives, partner, friends, work colleagues, general practitioner, psychiatrist, other physician, pharmacist, psychologist/ psychotherapist, school psychologist, priest/clerical counsellor, sect, alternative medicine and others. Previous or on-going medical treatment, especially antipsychotic treatment, earlier psychotherapy or other treatments are also actively inquired about.

\section{Definition of DUI/DUP}

Duration of untreated illness was defined as the time period between first selfperceived signs or symptoms of a change in well-being (even unspecific ones) and first contact with our specialised early detection clinic.

Duration of untreated psychosis was defined as the time period between the appearance of first psychotic symptoms and the first consultation with our early detection service. 


\section{Statistical analyses}

SPSS for Windows version 19 was used. Categorical data were analysed using chi-square tests or Fisher's exact test if expected cell frequencies were low. Because the continuous variables were not normally distributed, Mann-Whitney U-Test was used to compare ARMS individuals and FE patients as well as male and female participants on these variables. Correlational analyses were performed to assess associations between socio-demographic data and help-seeking variables. Due to the level of measurement, Spearman's correlational coefficient was chosen.

\section{Results}

\section{Sample characteristics}

Between 01.03.2000 and 29.02.2004, 234 individuals referred to our specialised clinic with suspected psychosis were screened (see Fig. 1).

There was no significant difference between participants and non-participants regarding age, or gender.

In this paper we present data of those 98 individuals (61 ARMS, $37 \mathrm{FE}$ ) with whom the BIP was conducted and of whom precise information about the helpseeking efforts could be obtained. Three ARMS individuals and nine FE patients could not give reliable information about their help seeking strategies and where therefore excluded from the help seeking analysis. They did not differ significantly from the examined individuals with regard to gender or other sociodemographic characteristics.

The sociodemographic characteristics of the sample are presented in Table 4 . There were no significant differences between FE and ARMS individuals regarding gender, however ARMS individuals were, as expected, significantly younger than FE patients. Moreover, FE patients were significantly less likely to be employed and lived alone more often than ARMS individuals.

Men were significantly more often unemployed than women independent of group affiliation. There were no further significant differences. 


\section{Duration of untreated illness (DUI)}

The median DUI was 41 months (mean \pm SD: $66.2 \pm 76.9$ ). DUI did not differ significantly between FE and ARMS (Mann-Whitney- $U$ : 846.0; $\mathrm{p}=0.872$ ), nor between men and women (Mann-Whitney $U: 817.0 ; \mathrm{p}=0.749$ ).

\section{Duration of untreated psychosis (DUP)}

On average DUP amounted to 46 months with a median of 12 months for the FE patients. This large discrepancy between mean and median DUP was due to a positively skewed distribution, caused by a small number of outliers (four FE patients with DUP over 7 years).

Concerning gender differences, the median value of DUP was 17 months (mean \pm SD: $57 \pm 91.7$ ) in men and 9 months (mean \pm SD: $27.6 \pm 52.2$ ) in women.

Due to the considerable range of the DUP a median split was adopted. The median for our FE group was 12 months and therefore a DUP $\leq 12$ months was defined as „short DUP“ and a DUP > 12 months as "long DUP”. Comparing short versus long DUP, no significant difference between men and women was found (Fisher's exact test $\mathrm{p}=0.064$ ).

\section{Referrals to our early detection clinic}

Most participants were referred to the early detection clinic via the University Psychiatric Outpatient Department of Basel $(n=32)$ or a psychiatrist in private practice $(\mathrm{n}=22)$. Referrals also came from other physicians including general practitioners $(n=13)$. Some individuals came on their own $(n=9)$ or on advice of relatives $(n=9)$. Further referrals came from other psychosocial institutions $(n=$ $3)$, a non-medical psychotherapist ( $\mathrm{n}=1)$ or other psychiatric institutions $(\mathrm{n}=1)$. Four persons could not give any information about their referral to the early detection clinic. 


\section{Main reasons for help-seeking}

Individuals were asked with a closed-ended question to give their main reasons leading to the consultation at the time of the interview. Up to three answers out of ten predetermined alternatives were possible. Onset or distinct increase of peculiarities in behaviour, appearance or speech were the most frequently mentioned reasons ( $53.3 \%$ of all cases), followed by $50.0 \%$ of all cases, who sought help because of self-perceived changes in well-being. Further reasons for consultations were attempted suicide, self-harming, signs or symptoms of a physical disease or recent changes or a crisis in the family/household of the patient. A detailed description of the main reasons comparing ARMS individuals and FE patients is shown in Table 5.

Table 5. Main reasons for consulting the psychiatric outpatient clinic

\section{Help-seeking pathways}

Help-seeking attempts prior to referral to our early detection clinic

$94.1 \%$ of the FE patients and $81.4 \%$ of the ARMS stated having at least one helpseeking effort before coming to the early detection clinic.

\section{Number of help-seeking contacts}

The number of help-seeking contacts prior to that with our early detection clinic ranged between zero and six. Contact with the Psychiatric University Outpatient Department of the Psychiatric University Clinics Basel subsequently followed by the referral within the same institution to the early detection clinic was defined as "one help-seeking effort".

Mean number of prior contacts for both, the FE patients and the ARMS individuals was 1.5 (median: 1). Most individuals had requested help once or twice (together 44.7\%) before contacting our specialised service. There were no significant between-group differences. Table 6 shows a detailed description of the number of help-seeking contacts for the different subgroups.

Gender comparison resulted in a significant difference in the number of helpseeking attempts between men and women (Mann-Whitney $U: 609.0 ; \mathrm{p} \square 0.001$ ), 
showing that women had requested help more often (on average 2.1 times) than men (1.2 times).

Table 6. Number of help-seeking contacts for the different subgroups

\section{Time between first help-seeking effort and consultation with the early detection clinic}

On average, the first help-seeking contact was 38 months (median 9 months) before consulting our specialised early detection clinic.

FE patients had requested help for the first time on average 52 months (median 7 months), ARMS individuals 30 months (median 11 months) beforehand. This delay was positively skewed (Kolmogorov-Smirnov-test: $\mathrm{p}<0.001$ ): $61 \%$ of the study population reached our specialised early detection clinic in less than one year, but about $20 \%$ needed over four years.

For women the first help-seeking attempt was 46 months before the first contact with our early detection clinic (median 11 months), for men 33 months (median 8 months).

There were neither significant differences between FE patients and ARMS $(\mathrm{p}=0.856)$, nor between men and women $(\mathrm{P}=0.574)$.

\section{Type of help-seeking contacts}

\section{First help-seeking contacts overall}

Tables 7 and 8 show the distribution of all first help-seeking contacts for the different subgroups. The most frequent first contacts were with family members or relatives, close friends, general practitioners or psychiatrists.

Altogether $45.6 \%$ sought help first from family members or close friends. This is nearly twice as much as first help-seeking attempts to professionals such as psychiatrists in private practice or general practitioners.

FE patients sought first help significantly more often within the family than ARMS individuals ( $\left.\square^{2}=5.88 ; \mathrm{df}=1 ; \mathrm{p}=0.015\right)$. 
Table 7. Comparison of help-seeking contacts between ARMS [2] and FE [43]

Table 8. Comparison of help-seeking contacts between men and women

The individuals who requested help first from a family member needed on average 42 months (median 12 months), those who first contacted close friends needed on average 12 months (median 6 months) before the first contact with our early detection clinic. For those seen first by a general practitioner the duration was on average 29 months (median 12 months). Those who had first contacted a psychiatrist in private practice needed on average 50 months (median 6 months) before referral to our early detection clinic. Further persons the individuals sought help from were partners, work colleagues, other physicians, psychologists/psychotherapists, school psychologists or priests/clerical counsellors.

\section{Subsequent help-seeking pathways}

Overall, the most frequent subsequent help-seeking contacts were with a psychiatrist in private practice $(\mathrm{n}=15 ; 38.5 \%$ of those with more than one helpseeking contact). Frequently, subsequent contact was also with a general practitioner $(n=9 ; 23.1 \%)$, friends $(n=8 ; 20.5 \%)$ or family members $(n=7$; $17.9 \%$ ). There were no significant differences, neither between the two study groups nor between men and women regarding subsequent help-seeking contacts. The most common contacts that finally resulted in referral to our specialised early detection clinic were psychiatrists $(23.1 \%)$, also family members $(14.3 \%)$, friends $(12.1 \%)$ or general practitioners $(11.0 \%)$. Overall, help-seeking contacts to nonmedical institutions such as those of alternative medicine were rare.

\section{Discussion}

We investigated in detail the pathways to care in individuals with emerging psychosis in an area with a well-developed, low threshold mental health care system, in which an early detection clinic was established accompanied by widespread information campaigns at the beginning of the study. The results 
showed the important role on the help-seeking pathway of family and friends as well as psychiatrists in private practice in the investigated area. Almost half of all individuals requested help first from a family member or from close friends followed by psychiatrists in private practice. Moreover, FE patients were more likely to seek help within the family than ARMS.

Comparing men and women we found a significant difference concerning helpseeking patterns: women had more help-seeking contacts than men before they presented to our early detection clinic.

Concerning the duration of untreated illness and psychosis (DUI, DUP), our results are in line with those of other studies. The median DUI was 41 months (SD \pm 77 ) for the whole study population with a wide range which is similar to results described earlier $[2,43]$. The median DUP of 12 months is similar to results of other studies $[32,44]$.

Also, our findings regarding referrals and main reasons for consultation are similar to results reported by others $[9,33,34]$. Most individuals were referred to our early detection clinic via the University Psychiatric Outpatient Department, where they sought help because of self-perceived signs or symptoms. Some individuals came on their own initiative directly to the early detection clinic or after advice from relatives. The most frequently mentioned reasons for the consultation are similar to findings in previous studies $[9,29,33,35]$.

Less than half of our patients needed more than one other help-seeking contact to finally reach our early detection clinic. This may be due to our intensive cooperation with general practitioners, psychiatrists in private practice and other institutions [37]. The amount of help-seeking contacts before we saw patients in our specialised clinic ranged between zero and six, which is similar to most other studies $[29,33,35]$ but some authors describe up to over forty help-seeking attempts $[31,45]$. Within the subsample of FE patients only $6 \%$ had not sought any help prior to referral to the early detection clinic. These are less than described in other studies where up to a third had not sought any other help previously $[9,29,44]$. This could be due to the low threshold mental health care 
system in Switzerland, where every inhabitant has an obligatory health care insurance and access to outpatient and specialised health care facilities. The threshold to access to specialised medical care is lower [46] than in other countries with more restrictive, canalised structures within the health care system, for example in Great Britain, USA or Australia.

The longest time to reach specialised care, in this report meaning our outpatient department, was for those who first saw a psychiatrist. It is to be expected that psychiatrists in private practice treat these patients themselves first and refer them later.possibly for a second opinion, or if the case is complex. We found that women initialised more help-seeking contacts than men. Women seem more likely to seek help from mental health professionals than men, maybe due to a more positive attitude towards health professionals and their being more open to psychology [47-49]. Despite this, earlier studies with large and representative samples have not found any sex differences in the DUP or DUI between men and women [50-55]. This is an interesting finding which seeks an explanation.

It may be useful to plan information campaigns in order to raise the knowledge about the necessity of help-seeking and establish early detection strategies which specifically target young men.

Concerning the first help-seeking effort, we found that it was mainly directed at a family member or significant other.

Two other studies provide data about non-medical first help-seeking contacts $[45,33]$. Whereas in our investigation almost half of the individuals declared a family member, partner or friend as a first help-seeking contact, the amount of such non-medical contacts were comparatively small in the studies of Lincoln and Addington. The proportion of consulted general practitioners or psychiatric professionals was higher than in our investigation. This may possibly be due to different methods of questioning and mapping the pathways to care.

The fact that general practitioners were contacted less often in our study than the ones mentioned above may be attributed to the gate-keeper role of general practitioners in Canada [33] and Australia [45], as described by Malla [8] earlier. 
In a Canadian sample of 35 clinical high risk individuals, it was found that the majority of contacts were made to general practitioners [56].

Considering only medical professionals as first help-seeking contact, many studies consistently report the important role of general practitioners, because they are most likely to be the first help-seeking contact [35,9,29,22]. Fuchs and Steinert [30] and Köhn [34] report different results from Germany. Both showed a higher frequency in consulting a psychiatrist in private practice first with $39.4 \%$ [30] and $23.8 \%$ [34]. Analysing only medical professionals as first help-seeking contact, we also found that a psychiatrist in private practice was most often consulted first, followed by a general practitioner. In the subsample of the FE patients, the first help-seeking contacts were equally distributed between psychiatrists in private practice $(12 \%)$ and general practitioners $(12 \%)$.

A tendency of more general help-seeking contacts in the beginning towards helpseeking from more specialised services later on, as described by other authors $[35,45,29]$ can be confirmed by our results. During the course of help-seeking, the spectrum of help-seeking contacts broadened, and other services such as a priest, school psychologist, other physicians or alternative medical facilities were contacted to obtain help.

\section{Limitations}

Finally, the limitations of this study should be mentioned. The data in this kind of study can only be collected retrospectively and therefore relies largely on recall precision. These findings on pathways to care and duration of untreated psychosis are predominantly based on patients' self-report. Apart from recall errors, also selective reporting can be a problem.

Another weakness is the modest sample size, which leads to limited statistical power.

Pathways to care were studied in those patients who were referred to our specialised early detection clinic. Due to the large number of psychiatrists in 
private practice in the area, we cannot exclude that there may be a selection bias, i.e. there could be (pre)psychotic patients who are treated by private psychiatrists and are not referred to our early detection service.

Finally, structure and accessibility of the mental health care system varies across countries. Thus, not all our findings can be directly compared with results from other studies.

\section{Conclusions}

Our study confirms the importance of a specialised early detection service for psychosis. It is necessary to continue early detection programs and information campaigns to increase the knowledge about schizophrenic psychoses and the necessity of adequate treatment. Investigating gender differences in help seeking could help to understand obstacles in getting help.

\section{Acknowledgements}

We thank all participating patients, our colleagues for conducting interviews. Thanks also to Claudine Pfister for her help in preparing the manuscript. 
Table 1. Inclusion criteria for $\mathrm{ARMS}^{\S}$ individuals

Individuals were classified as ARMS if they met the following inclusion criteria

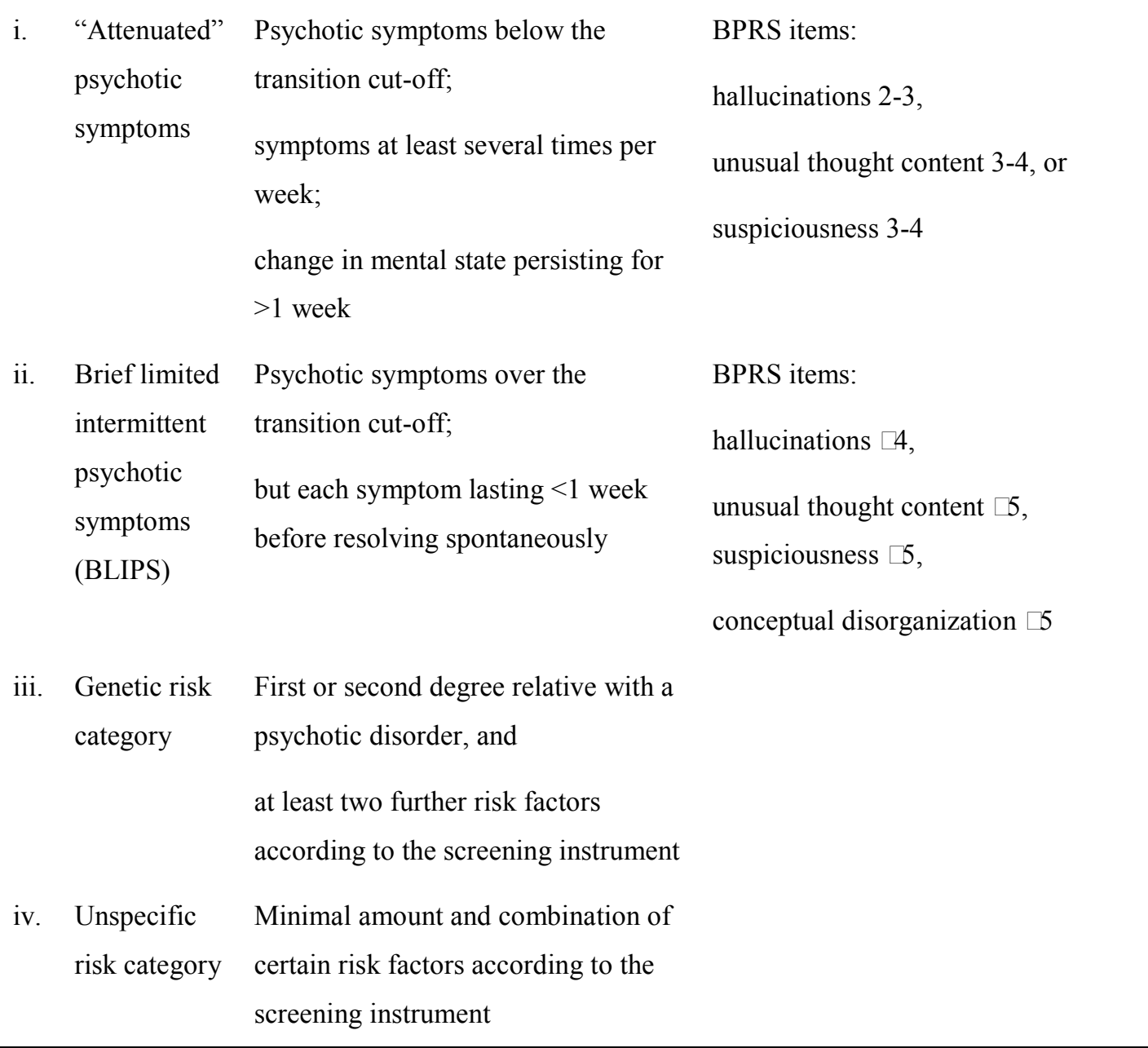

Criteria i), ii) and iii) correspond to those of Yung et al. [36]; and BRPS = Brief Psychiatric Rating Scale (version Lukoff et al. 1986 [57]). Criterion iv) permits the additional inclusion of individuals at presumably lower risk, i.e. of individuals without pre-psychotic symptoms or genetic risk who only have a combination of certain unspecific risk factors and indicators, such as prodromal symptoms and/or marked social decline.

${ }^{\S} \mathrm{ARMS}=$ individuals with an at-risk mental state 
Table 2: Transition criteria for $\mathrm{FE}^{*}$ patients

Patients meeting the following criteria were considered to have made the transition to psychosis and were therefore classified as FE patients

i. At least one of the following symptoms:

- $\quad$ Suspiciousness

BPRS $\square 5$

- Unusual thought content

BPRS $\square 5$

- Hallucinations

BPRS $\square 4$

- Conceptual disorganisation

BPRS $\square 5$

ii. The symptoms are present at least several times a week

The change in mental state lasts $>1$ week

${ }^{\star} \mathrm{FE}=$ first episode psychosis

According to Yung et al 1998 and BRPS = Brief Psychiatric Rating Scale (version Lukoff et al. $1986[57])$ 
Table 3. Overview of clinical ICD-10 diagnoses in the FE $\$$ group $(\mathrm{N}=37)^{*}$

\begin{tabular}{lll}
\hline ICD-10 Code & Diagnoses & Number \\
\hline F20.09 & schizophrenia unspecified & 8 \\
F 20.0 & paranoid schizophrenia & 13 \\
F 20.1 & hebephrenic schizophrenia & 2 \\
F 21 & schizotypal disorder & 5 \\
F 23.1 & acute polymorph psychotic disorder with symptoms of \\
& schizophrenia & \\
F 23.2 & acute schizophrenia-like psychotic disorder & 2 \\
F 25 & schizoaffective disorder & 2 \\
F 22.0 & delusional disorder
\end{tabular}

$\ddagger \mathrm{FE}=$ first episode psychosis patients

*3 cases with no valid information of diagnosis at screening, only transition criteria fulfilled 
Table 4: Socio-demographic characteristics ${ }^{*}$

\begin{tabular}{|c|c|c|c|}
\hline & $\begin{array}{l}\mathrm{ARMS}^{\S} \\
(\mathrm{n}=61)^{\dagger}\end{array}$ & $\begin{array}{c}\mathrm{FE}^{\ddagger} \\
(\mathrm{n}=37)^{\dagger}\end{array}$ & Significance value \\
\hline Age & $26.8 \pm 8.7$ & $31.0 \pm 8.5$ & $\begin{array}{c}\text { Mann-Whitney U: } \\
766.0 ; p=0.008\end{array}$ \\
\hline Men & $36(59.0)$ & $25(67.6)$ & $\begin{array}{c}\cdot^{2}: 0.7 ; \mathrm{df}=1 ; \mathrm{p}= \\
0.397\end{array}$ \\
\hline Women & $25(41.0)$ & $12(32.4)$ & \\
\hline \multicolumn{4}{|l|}{ Educational level } \\
\hline$<9$ years & $20(32.8)$ & $16(43.2)$ & $\begin{array}{c}\cdot^{2}: 1.5 ; \mathrm{df}=3 ; \mathrm{p}= \\
0.677\end{array}$ \\
\hline $9-11$ years & $20(32.8)$ & $10(27.0)$ & \\
\hline $12-13$ years & $14(23.0)$ & $6(16.2)$ & \\
\hline $14-20$ years & $7(11.5)$ & $5(13.5)$ & \\
\hline \multicolumn{4}{|l|}{ Employment status } \\
\hline Unemployed & $15(26.8)$ & $16(50.0)$ & $\begin{array}{c}\cdot^{2}: 4.8 ; \mathrm{df}=1 ; \mathrm{p}= \\
0.028\end{array}$ \\
\hline Employed & $41(73.2)$ & $16(50.0)$ & \\
\hline
\end{tabular}

Is the person able to earn his/her living?

\begin{tabular}{lccc}
\hline Yes & $21(35.0)$ & $9(25.0)$ & $\bullet^{2}: 1.0 ; \mathrm{df}=1 ; \mathrm{p}=$ \\
0.306 & \\
\hline No & $39(65.0)$ & $27(77.0)$ & \\
\hline Residential status & & & \\
\hline Living alone & $18(29.5)$ & $18(50.0)$ & $\bullet^{2}: 4.1 ; \mathrm{df}=1 ; \mathrm{p}=$ \\
Not living alone & $43(70.5)$ & $18(50.0)$ & 0.044 \\
\hline
\end{tabular}

*Values are given as mean $\pm \mathrm{SD}$ or percentage (in brackets)

${ }^{\S} \mathrm{ARMS}=$ individuals with an at-risk mental state

${ }^{\ddagger} \mathrm{FE}=$ first episode psychosis patients

${ }^{\dagger}$ Incongruent $\mathrm{N}$ is due to missing data 
Table 5: Main reasons for consulting the psychiatric outpatient clinic

\begin{tabular}{|c|c|c|c|}
\hline & $\mathrm{ARMS}^{\S}$ & $\mathrm{FE}^{*}$ & $P$-value \\
\hline & $\mathrm{n}=56$ & $\mathrm{n}=36$ & \\
\hline & (\% of all cases) & ( $\%$ of all cases $)$ & \\
\hline Onset/increase of "peculiarity" & $32(57.1)$ & $17(47.2)$ & 0.352 \\
\hline \multicolumn{4}{|l|}{ behaviour } \\
\hline Other reasons & $9(16.1)$ & $8(22.2)$ & 0.458 \\
\hline Attempted suicide & $3(5.4)$ & 0 & $0.278^{\dagger}$ \\
\hline Self-endangering behaviour & $3(5.4)$ & $2(5.6)$ & $1^{\dagger}$ \\
\hline No current reason & $2(3.6)$ & 0 & $0.518^{\dagger}$ \\
\hline Change/crisis in family/ & $2(3.6)$ & 0 & $0.518^{\dagger}$ \\
\hline \multicolumn{4}{|l|}{ household of the patient } \\
\hline $\begin{array}{l}\text { Signs/symptoms of physical } \\
\text { disease }\end{array}$ & 0 & $1(2.8)$ & $0.391^{\dagger}$ \\
\hline
\end{tabular}

\footnotetext{
${ }^{\S} \mathrm{ARMS}=$ individuals with an at-risk mental state

${ }^{\dagger} \mathrm{FE}=$ first episode psychosis patients

Percentages add up to more than $100 \%$, because up to three reasons could be declared

${ }^{\dagger}$ Fisher exact test
} 
Table 6: Number of help-seeking contacts for the different subgroups

\begin{tabular}{|c|c|c|c|c|c|c|c|}
\hline & $\begin{array}{l}\text { Total }^{\dagger} \\
\mathrm{n}=94\end{array}$ & $\begin{array}{l}\mathrm{ARMS}^{\S} \\
\mathrm{n}=60\end{array}$ & $\begin{array}{c}\mathrm{FE}^{*} \\
\mathrm{n}=34\end{array}$ & $\begin{array}{c}\text { Significance } \\
\text { value }\end{array}$ & $\begin{array}{c}\text { Female } \\
\mathrm{n}=35\end{array}$ & $\begin{array}{l}\text { Male } \\
\mathrm{n}=59\end{array}$ & $\begin{array}{c}\text { Significance } \\
\text { value }\end{array}$ \\
\hline \multirow[t]{4}{*}{ Zero } & 13 & 11 & 2 & Mann-Whitney & 2 & 11 & Mann- \\
\hline & & & & $U: 695.5$ & & & Whitney $U$ : \\
\hline & & & & $\mathrm{p}=0.650$ & & & 609.0; \\
\hline & & & & & & & $\mathrm{p}<0.001$ \\
\hline One & 42 & 24 & 18 & & 11 & 31 & \\
\hline Two & 21 & 13 & 8 & & 10 & 11 & \\
\hline Three & 13 & 8 & 5 & & 8 & 5 & \\
\hline Four & 4 & 3 & 1 & & 3 & 1 & \\
\hline $\operatorname{Six}^{*}$ & 1 & 1 & 0 & & 1 & 0 & \\
\hline
\end{tabular}

'Some individuals could not provide this information

${ }^{\S}$ ARMS $=$ individuals with an at-risk mental state

${ }^{\ddagger} \mathrm{FE}=$ first episode psychosis patients

*No individual made five help-seeking contacts 
Table 7: Comparison of first help-seeking contacts between $\mathrm{ARMS}^{\S}$ and $\mathrm{FE}^{\star}$

\begin{tabular}{lccc}
\hline & $\begin{array}{c}\text { ARMS } \\
\mathrm{n}=56\end{array}$ & $\begin{array}{c}\mathrm{FE} \\
\mathrm{n}=34\end{array}$ & $P$-value \\
& $10(17.9)$ & $14(41.2)$ & 0.015 \\
\hline Family/relatives & $10(17.9)$ & $7(20.6)$ & 0.748 \\
Friends & $9(16.1)$ & $4(11.8)$ & $0.759 \dagger$ \\
Psychiatrist & $7(12.5)$ & $4(11.8)$ & $1 \dagger$ \\
General practitioner & $1(1.8)$ & 0 & $1 \dagger$ \\
Colleagues from work & $2(3.6)$ & $2(5.9)$ & $0.631 \dagger$ \\
Partner & $3(5.4)$ & 0 & $0.287 \dagger$ \\
Other physician & $2(3.6)$ & 0 & $0.525 \dagger$ \\
Psychologist/psychotherapist & 0 & $1(2.9)$ & $0.378 \dagger$ \\
School psychologist & $11(19.6)$ & $2(5.9)$ & $1 \dagger$ \\
Priest & 0 & 0 & $0.12 \dagger$ \\
Alternative medicine & & 0 & \\
No help-seeking contact & & 0 & \\
\hline
\end{tabular}

${ }^{\S} \mathrm{ARMS}=$ individuals with an at-risk mental state

${ }^{\ddagger} \mathrm{FE}=$ first episode psychosis patients

${ }^{\dagger}$ Fisher exact test 
Table 8. Comparison of first help-seeking contacts between women and men

\begin{tabular}{|c|c|c|c|}
\hline & $\begin{array}{c}\text { Women } \\
n=34 \\
(\%)\end{array}$ & $\begin{array}{c}\text { Men } \\
\mathrm{n}=56 \\
(\%)\end{array}$ & $P$-value \\
\hline Family/relatives & $9(26.5)$ & $15(26.8)$ & 0.974 \\
\hline Friends & $7(20.6)$ & $10(17.9)$ & 0.748 \\
\hline Psychiatrist & $7(20.6)$ & $6(10.7)$ & $0.226 \dagger$ \\
\hline General practitioner & $3(8.8)$ & $8(14.3)$ & $0.524 \dagger$ \\
\hline Colleagues from work & 0 & $1(1.8)$ & $1 \dagger$ \\
\hline Partner & $3(8.8)$ & $1(1.8)$ & $0.149 \dagger$ \\
\hline Other physician & $2(5.9)$ & $1(1.8)$ & $0.554 \dagger$ \\
\hline $\begin{array}{l}\text { Psychologist/ } \\
\text { psychotherapist }\end{array}$ & $1(2.9)$ & $1(1.8)$ & $1 \dagger$ \\
\hline School psychologist & 0 & $1(1.8)$ & $1 \dagger$ \\
\hline Priest & 0 & $1(1.8)$ & $1 \dagger$ \\
\hline Alternative medicine & 0 & 0 & $1 \dagger$ \\
\hline No help-seeking contact & $2(5.9)$ & $11(19.6)$ & $0.12 \dagger$ \\
\hline
\end{tabular}

${ }^{\dagger}$ Fisher exact test 


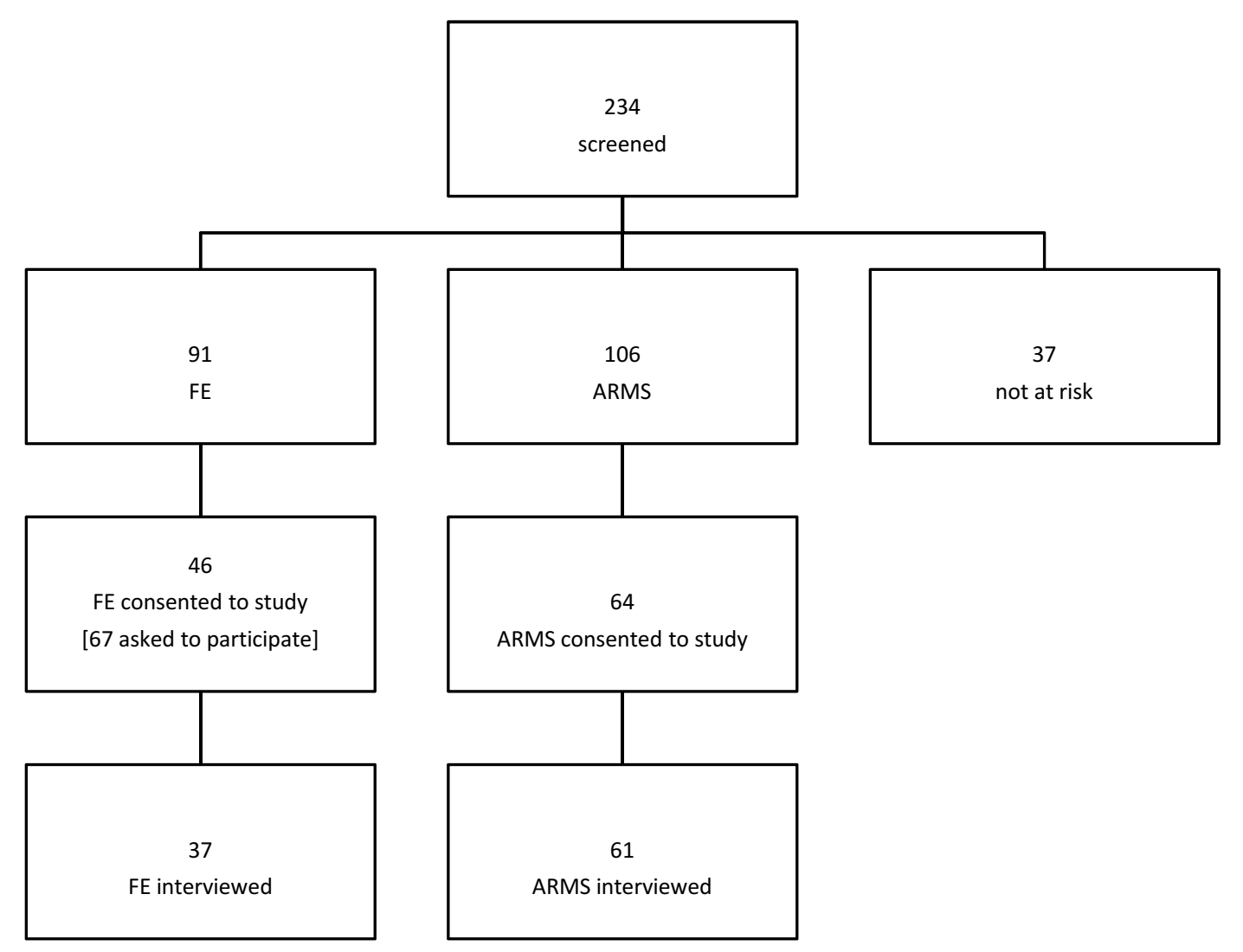

Figure 1 Overview of the recruitment process of the study sample (ARMS = individuals with an at-risk mental state; $\mathrm{FE}=$ first episode psychosis patients) 


\section{References}

1. Norman RM, Scholten DJ, Malla AK, Ballageer T (2005) Early signs in schizophrenia spectrum disorders. J Nerv Ment Dis 193 (1):17-23. doi:00005053200501000-00004 [pii]

2. Riecher-Rössler A, Gschwandtner U, Borgwardt S, Aston J, Pflüger M, Rössler W (2006) Early detection and treatment of schizophrenia: how early? Acta Psychiatr Scand Suppl (429):73-80. doi:ACP722 [pii]10.1111/j.16000447.2005.00722.x

3. Häfner H, Maurer K, Löffler W, an der Heiden W, Munk-Jorgensen P, Hambrecht M, Riecher-Rössler A (1998) The ABC Schizophrenia Study: a preliminary overview of the results. Soc Psychiatry Psychiatr Epidemiol 33 (8):380-386

4. Norman RM, Malla AK (2001) Duration of untreated psychosis: a critical examination of the concept and its importance. Psychol Med 31 (3):381-400

5. Marshall M, Lewis S, Lockwood A, Drake R, Jones P, Croudace T (2005) Association between duration of untreated psychosis and outcome in cohorts of first-episode patients: a systematic review. Arch Gen Psychiatry 62 (9):975-983. doi:62/9/975 [pii]10.1001/archpsyc.62.9.975

6. Schaffner N, Schimmelmann BG, Niedersteberg A, Schultze-Lutter F (2011) Versorgungswege von erstmanifesten psychotischen Patienten - eine Übersicht internationaler Studien. Pathways-to-Care for First-Episode Psychotic Patients An Overview of International Studies. Fortschr Neurol Psychiatr epub. doi:http://dx.doi.org/10.1055/s-0031-1273428

7. Häfner H, Riecher-Rössler A, Hambrecht M, Maurer K, Meissner S, Schmidtke A, Fatkenheuer B, Löffler W, van der Heiden W (1992) IRAOS: an instrument for the assessment of onset and early course of schizophrenia. Schizophr Res 6 (3):209-223

8. Malla A, Payne J (2005) First-episode psychosis: psychopathology, quality of life, and functional outcome. Schizophr Bull 31 (3):650-671. doi:sbi031 [pii]10.1093/schbul/sbi031

9. $\quad$ Norman RM, Malla AK, Verdi MB, Hassall LD, Fazekas C (2004) Understanding delay in treatment for first-episode psychosis. Psychol Med 34 (2):255-266

10. Perkins DO, Gu H, Boteva K, Lieberman JA (2005) Relationship between duration of untreated psychosis and outcome in first-episode schizophrenia: a critical review and meta-analysis. Am J Psychiatry 162 (10):1785-1804. doi:162/10/1785 [pii]10.1176/appi.ajp.162.10.1785

11. Marshall M, Rathbone J (2006) Early intervention for psychosis. Cochrane Database Syst Rev (4):CD004718. doi:10.1002/14651858.CD004718.pub2

12. Yung AR, Killackey E, Hetrick SE, Parker AG, Schultze-Lutter F, Klosterkoetter J, Purcell R, McGorry PD (2007) The prevention of schizophrenia. Int Rev Psychiatry 19 (6):633-646. doi:788631597 [pii]10.1080/09540260701797803

13. Drake RJ, Lewis SW (2005) Early detection of schizophrenia. Curr Opin Psychiatry 18 (2):147-150. doi:00001504-200503000-00007 [pii]

14. Boonstra N, Klaassen R, Sytema S, Marshall M, De Haan L, Wunderink L, Wiersma D (2012) Duration of untreated psychosis and negative symptoms - A systematic review and meta-analysis of individual patient data. Schizophr Res. doi:S0920-9964(12)00498-7 [pii] 10.1016/j.schres.2012.08.017

15. Schmitz N, Malla A, Norman R, Archie S, Zipursky R (2007) Inconsistency in the relationship between duration of untreated psychosis (DUP) and negative symptoms: sorting out the problem of heterogeneity. Schizophr Res 93 (1-3):152159. doi:S0920-9964(07)00131-4 [pii]10.1016/j.schres.2007.03.021 
16. Macdonald EM, Hayes RL, Baglioni AJ, Jr. (2000) The quantity and quality of the social networks of young people with early psychosis compared with closely matched controls. Schizophr Res 46 (1):25-30. doi:S0920-9964(00)00024-4 [pii]

17. Garety PA, Rigg A (2001) Early psychosis in the inner city: a survey to inform service planning. Soc Psychiatry Psychiatr Epidemiol 36 (11):537-544

18. Häfner H, Maurer K, Löffler W, an der Heiden W, Hambrecht M, Schultze-Lutter F (2003) Modeling the early course of schizophrenia. Schizophr Bull 29 (2):325340

19. Häfner H, Maurer K, Löffler W, Bustamante S, van der Heiden W, RiecherRössler A, Nowotny B (1995) Onset and Early Course of Schizophrenia. In: Häfner H, Gattaz WF (eds) Search for the Causes of Schizophrenia, vol III. Springer, Berlin, Heidelberg, New York, pp 43-46

20. Lincoln CV, McGorry P (1995) Who cares? Pathways to psychiatric care for young people experiencing a first episode of psychosis. Psychiatr Serv 46 (11):1166-1171

21. Singh SP, Grange T (2006) Measuring pathways to care in first-episode psychosis: a systematic review. Schizophr Res 81 (1):75-82. doi:S09209964(05)00462-7 [pii]10.1016/j.schres.2005.09.018

22. Steel Z, McDonald R, Silove D, Bauman A, Sandford P, Herron J, Minas IH (2006) Pathways to the first contact with specialist mental health care. Aust N Z J Psychiatry 40 (4):347-354. doi:ANP1801 [pii]10.1111/j.1440-1614.2006.01801.x

23. Issakidis C, Andrews G (2006) Who treats whom? An application of the Pathways to Care model in Australia. Aust N Z J Psychiatry 40 (1):74-86. doi:ANP1746 [pii]10.1111/j.1440-1614.2006.01746.x

24. Riecher-Rössler A (2005) Früherkennung schizophrener Psychosen. In: RiecherRössler A, Bitzer J (eds) Frauengesundheit. Ein Leitfaden für die ärztliche und psychotherapeutische Praxis. Elsevier, Urban \& Fischer, München, Jena, pp 522533

25. Rietdijk J, Hogerzeil SJ, van Hemert AM, Cuijpers P, Linszen DH, van der Gaag M (2011) Pathways to psychosis: help-seeking behavior in the prodromal phase. Schizophr Res 132 (2-3):213-219. doi:S0920-9964(11)00443-9 [pii]10.1016/j.schres.2011.08.009

26. Skeate A, Jackson C, Birchwood M, Jones C (2002) Duration of untreated psychosis and pathways to care in first-episode psychosis. Investigation of helpseeking behaviour in primary care. Br J Psychiatry Suppl 43:s73-77

27. Bodenheimer TS, Grumbach K (2005) Understanding health policy. A clinical approach. Lange Medical books/Mc Graw-Hill, New York

28. Rädler T, Naber D (2007) Schizophrenie. In: Rohde A, Marneros A (eds) Geschlechtsspezifische Psychiatrie und Psychotherapie. Ein Handbuch.

Kohlhammer, Stuttgart, pp 50-59

29. Platz C, Umbricht DS, Cattapan-Ludewig K, Dvorsky D, Arbach D, Brenner HD, Simon AE (2006) Help-seeking pathways in early psychosis. Soc Psychiatry Psychiatr Epidemiol 41 (12):967-974. doi:10.1007/s00127-006-0117-4

30. Fuchs J, Steinert T (2004) Patients with a first episode of schizophrenia spectrum psychosis and their pathways to psychiatric hospital care in South Germany. Soc Psychiatry Psychiatr Epidemiol 39 (5):375-380. doi:10.1007/s00127-004-0767-z

31. Turner M, Smith-Hamel C, Mulder R (2006) Pathways to care in a New Zealand first-episode of psychosis cohort. Aust N Z J Psychiatry 40 (5):421-428. doi:ANP1818 [pii]10.1111/j.1440-1614.2006.01818.x

32. Phillips L, Yung AR, Hearn N, McFarlane C, Hallgren M, McGorry PD (1999) Preventative mental health care: accessing the target population. Aust N Z J Psychiatry 33 (6):912-917

33. Addington J, Van Mastrigt S, Hutchinson J, Addington D (2002) Pathways to care: help seeking behaviour in first episode psychosis. Acta Psychiatr Scand 106 (5):358-364. doi:2o004 [pii] 
34. Köhn D, Pukrop R, Niedersteberg A, Schultze-Lutter F, Ruhrmann S, Bechdolf A, Berning J, Maier W, Klosterkötter J (2004) [Pathways to care: help-seeking behavior in first-episode psychosis]. Fortschr Neurol Psychiatr 72 (11):635-642. doi:10.1055/s-2004-818418

35. Cougnard A, Kalmi E, Desage A, Misdrahi D, Abalan F, Brun-Rousseau H, Salmi LR, Verdoux H (2004) Pathways to care of first-admitted subjects with psychosis in South-Western France. Psychol Med 34 (2):267-276

36. Yung AR, Phillips LJ, McGorry PD, McFarlane CA, Francey S, Harrigan S, Patton GC, Jackson HJ (1998) Prediction of psychosis. A step towards indicated prevention of schizophrenia. Br J Psychiatry Suppl 172 (33):14-20

37. Riecher-Rössler A, Gschwandtner U, Aston J, Borgwardt S, Drewe M, Fuhr P, Pflüger M, Radü W, Schindler C, Stieglitz RD (2007) The Basel early-detectionof-psychosis (FEPSY)-study--design and preliminary results. Acta Psychiatr Scand 115 (2):114-125. doi:ACP854 [pii]10.1111/j.1600-0447.2006.00854.x

38. Riecher-Rössler A (2008) Strategies for improving the prediction of psychosis. Schizophr Res 102 (Suppl. 2):155

39. Riecher-Rössler A, Pflueger MO, Aston J, Borgwardt SJ, Brewer WJ, Gschwandtner U, Stieglitz RD (2009) Efficacy of using cognitive status in predicting psychosis: a 7-year follow-up. Biol Psychiatry 66 (11):1023-1030. doi:S0006-3223(09)00894-4 [pii]10.1016/j.biopsych.2009.07.020

40. Riecher-Rössler A, Aston J, Ventura J, Merlo M, Borgwardt S, Gschwandtner U, Stieglitz RD (2008) [The Basel Screening Instrument for Psychosis (BSIP): development, structure, reliability and validity]. Fortschr Neurol Psychiatr 76 (4):207-216. doi:10.1055/s-2008-1038155

41. Yung AR, Yuen HP, McGorry PD, Phillips LJ, Kelly D, Dell'Olio M, Francey SM, Cosgrave EM, Killackey E, Stanford C, Godfrey K, Buckby J (2005) Mapping the onset of psychosis: the Comprehensive Assessment of At-Risk Mental States. Aust N Z J Psychiatry 39 (11-12):964-971. doi:ANP1714 [pii] 10.1111/j.1440-1614.2005.01714.x

42. World Health Organisation. The ICD-10 classification of mental and behavioral disorders. World Health Organisation, Geneva

43. Häfner H, Maurer K (2006) Early detection of schizophrenia: current evidence and future perspectives. World Psychiatry 5 (3):130-138

44. Larsen TK, Johannessen JO, Opjordsmoen S (1998) First-episode schizophrenia with long duration of untreated psychosis. Pathways to care. Br J Psychiatry Suppl 172 (33):45-52

45. Lincoln C, Harrigan S, McGorry PD (1998) Understanding the topography of the early psychosis pathways. An opportunity to reduce delays in treatment. $\mathrm{Br} \mathrm{J}$ Psychiatry Suppl 172 (33):21-25

46. Simon AE, Lauber C, Ludewig K, Braun-Scharm H, Umbricht DS (2005) General practitioners and schizophrenia: results from a Swiss survey. Br J Psychiatry 187:274-281. doi:187/3/274 [pii]10.1192/bjp.187.3.274

47. Ernst C (2001) Geschlechtsunterschiede bei psychischen Erkrankungen. Die bessere und die schlechtere Hälfte? Geschlechtsunterschiede in der Prävalenz psychischer Krankheiten aus epidemiologischer Sicht. In: Riecher-Rössler A, Rohde A (eds) Psychische Erkrankungen bei Frauen. Für eine geschlechtersensible Psychiatrie und Psychotherapie. Karger, Basel, Freiburg (Breisgau), Paris, London, New York, New Delhi, Bangkok, Singapore, Tokyo, Sydney, pp 47-61

48. Mackenzie CS, Gekoski WL, Knox VJ (2006) Age, gender, and the underutilization of mental health services: the influence of help-seeking attitudes. Aging Ment Health 10 (6):574-582. doi:M0222V7376P5M826 [pii]; $10.1080 / 13607860600641200$

49. Riecher-Rössler A, Bitzer J (eds) (2005) Frauengesundheit. Ein Leitfaden für die ärztliche und psychotherapeutische Praxis. Urban \& Fischer, München 
50. Häfner H, Riecher A, Maurer K, Löffler W, Munk-Jorgensen P, Stromgren E (1989) How does gender influence age at first hospitalization for schizophrenia? A transnational case register study. Psychol Med 19 (4):903-918

51. Häfner H, Riecher A, Maurer K, Fatkenheuer B, Löffler W, an der Heiden W, Munk-Jorgensen P, Stromgren E (1991) Geschlechtsunterschiede bei schizophrenen Erkrankungen ([Sex differences in schizophrenic diseases]). Fortschr Neurol Psychiatr 59 (9):343-360

52. Riecher A, Maurer K, Löffler W, Fätkenheuer B, an der Heiden W, MunkJorgensen P, Strömgren E, Häfner H (1991) Gender differences in age at onset and course of schizophrenic disorders. In: Häfner H, Gattaz WF (eds) Search for the causes of schizophrenia, vol 2. Springer, Berlin, Heidelberg, pp 14-33

53. Häfner H, Maurer K, Löffler W, Riecher-Rössler A (1993) The influence of age and sex on the onset and early course of schizophrenia. Br J Psychiatry 162:80-86

54. Häfner H, an der Heiden W, Behrens S, Gattaz WF, Hambrecht M, Löffler W, Maurer K, Munk-Jorgensen P, Nowotny B, Riecher-Rössler A, Stein A (1998) Causes and consequences of the gender difference in age at onset of schizophrenia. Schizophr Bull 24 (1):99-113

55. Häfner H, Riecher-Rössler A, An Der Heiden W, Maurer K, Fatkenheuer B, Löffler W (1993) Generating and testing a causal explanation of the gender difference in age at first onset of schizophrenia. Psychol Med 23 (4):925-940

56. Stowkowy J, Colijn MA, Addington J (2012) Pathways to care for those at clinical high risk of developing psychosis. Early Interv Psychiatry. doi:10.1111/j.1751-7893.2012.00368.x

57. Lukoff D, Nuechterlein KH, Ventura J (1986) Manual for the expanded brief psychiatric rating scale. Schizophr Bull 12:594-602 